\title{
Antarctica SED/TOI associated ionospheric scintillation during 27 February 2014 geomagnetic storm
}

\author{
S. Priyadarshi ${ }^{1} \cdot$ Q.-H. Zhang ${ }^{2} \cdot$ Y.-Z. $\mathrm{Ma}^{2}$
}

Received: 11 August 2018 / Accepted: 30 November 2018 / Published online: 4 December 2018

(c) The Author(s) 2018

\begin{abstract}
A geomagnetic storm occurred on 27 February 2014 and the shock related to it arrived at Earth's magnetosphere at $\sim$ 17:00 UT. Dayside cusp region scintillation over Antarctica have been studied along with the Global Positioning System (GPS) observed total electron content (TEC), and Defense Meteorological Satellite Program (DMSP) Precipitating Particles (SSJ), Bulk Plasma Parameters (SSIES) and Magnetic Fields (SSM) data. For the first time, similar variation trend in amplitude and phase scintillation has been found near the polar latitude. Amplitude scintillation index $\left(\mathrm{S}_{4}\right)$ and phase scintillation index $\left(\sigma_{\varphi}\right)$ show the similar enhancement trend at different numerical scale. During the southward interplanetary magnetic field (IMF) Bz condition there is a significant enhancement in the particle precipitation occurred through the dayside cusp region. During southward IMF Bz and dawnward By $(\mathrm{By}<0)$, high convection velocity guide solar wind plasma into the polar cap which enhances the phase scintillation, but, no amplitude scintillation enhancement at the similar numerical scale. The Halley and Dome C East radar data show that at the small to medium ionospheric irregularity speed, $\mathrm{S}_{4}$, and $\sigma_{\varphi}$ variations are alike. If proper variation scale is chosen, $\mathrm{S}_{4}$ also appears an appropriate scintillation index for the polar ionosphere. The possible mechanism for $\mathrm{S}_{4}$ occurrence similar to the $\sigma_{\varphi}$ at a dissimilar level has been discussed.
\end{abstract}

\footnotetext{
S. Priyadarshi

shishir.priyadarshi@uwr.edu.pl

$凶$ Q.-H. Zhang

zhangqinghe@sdu.edu.cn

1 Department of Climatology and Atmospheric Protection, University of Wroclaw, Kosiby 8 Wroclaw 51-621, Poland

2 Shandong Provincial Key Laboratory of Optical Astronomy and Solar-Terrestrial Environment, Institute of Space Sciences, Shandong University, Weihai, China
}

Key points:

1. Dayside cusp region amplitude and phase scintillation indices give similar information but at different numerical scale during the geomagnetic storm onset.

2. Amplitude scintillation index is also an appropriate scintillation index for high latitude if proper numerical scales are chosen.

3. SED or TOI does not necessarily produce ionospheric scintillation.

4. Southward IMF Bz and westward IMF By allows the scintillation producing ionospheric irregularities to pass in deep inside the South Pole.

Keywords South Pole $\cdot$ Scintillation $\cdot$ SED $\cdot$ TOI · GPS · Geomagnetic storm · Dayside cusp

\section{Introduction}

Space weather community extensively uses indices $\mathrm{S}_{4}$ and $\sigma_{\varphi}$ for quantifying amplitude and phase scintillation index, respectively; on the GNSS radio trans-ionospheric communication signal. Where $S_{4}$ is the ratio of the standard deviation of the received signal power over the average signal power and $\sigma_{\varphi}$ is the standard deviation of the received signal phase (Van Dierendonck et al. 1993). The polar ionosphere is known to have ionospheric scintillation on the trans-ionospheric radio wave communication signal during all local times (Basu et al. 2002; Wernik et al. 2004). Further, ionospheric scintillation in the polar ionosphere has been studied extensively, and it is widely believed that strong amplitude scintillation at GPS L-band frequency rarely occurs at the high latitudes; because of this, it is popular to investigate phase scintillation only during the high latitude ionospheric events (Spogli et al. 2009; Li et al. 2010; Prikryl 
et al. 2010; Moen et al. 2013). However, in general, it is unidentified of any value in considering these two indices as being in competition. In practice they are complementary, each of these indices measures different consequences of ionospheric scintillation. Those differences have distinct impacts on trans-ionospheric radio signals. For example on GNSS signals, phase scintillation contributes directly to position uncertainties and, in extreme cases, it can cause receivers to lose phase lock, even if signal strength itself is adequate. In contrast, amplitude scintillation is an issue when it significantly reduces the signal strength. From the last 1-2 decades, space weather researchers are mostly studying the phase scintillation for the high latitude and space physics community mainly focuses on the phase scintillation index for studying the polar ionospheric responses during the active solar events such as geomagnetic storm, solar flares, Earth-directed CMS's etc. Kinrade et al. (2012) studied storm-time ionospheric scintillation over Antarctica on 5-6 April 2010 and reported the scintillation occurrence in the deep polar cap 40 minutes after the shock front was recorded by a satellite at 1 st Lagrangian orbit. This scintillation activity continued for few hours in the dayside. Kinrade et al. (2012) also reported that the scintillation was coincident with the plasma depletion region in the dayside noon as well as dayside cusp region. Prikryl et al. (2015a) studied GPS phase scintillation at the northern high latitude during the geomagnetic storm of 7-17 March 2012. The study carried out by Prikryl et al. (2015a) reported that the strong southward IMF and high solar dynamic pressure causes strong scintillation, which was coincident with the ionospheric convection in the dawn-dusk cells, together with the antisunward convection patches in the tongue of ionization and the polar cap. Prikryl et al. (2016, 2015b) reported two geomagnetic storms associated high latitude phase scintillation case studies on November 1, 2011, and March 17, 2013. Prikryl et al. (2015a, 2015b) also reported that $\sigma_{\varphi}$ in polar cap of the southern hemisphere were tilted toward dusk when the IMF By is duskward $(\mathrm{By}>0)$ or toward dawn when the IMF By is dawnward $(\mathrm{By}<0)$. Further, Prikryl et al. (2015a, 2015b) stated the enhanced phase scintillation related with the storm-enhanced density (SED) and fragmented tongue of ionization into patches. Strong scintillation was coincident with the strong poleward flow and the polar cap. Moderate to strong phase scintillation observed at the dawn side convection cell. Whereas, weak scintillation have been observed near the polar side of the subauroral polarization stream (SAPS). Wang et al. (2016) found Arctic region $\sigma_{\varphi}>\mathrm{S}_{4}$ at the edges of the irregularities associated with bursty flows; and $\sigma_{\varphi} \gg \mathrm{S}_{4}$ in the auroral oval. Jin et al. (2017) reported scintillation associated with the cusp region as well as the polar cap patches and mentioned that scintillation was more severe when patches were entering in the polar cap and targeted by the particle precipitation and flow shears. D'Angelo et al. (2018) used multi-instrument observations and reported the Antarctic ionosphere mostly responsive to the solar perturbations triggered storm. In this study, they demonstrated the usefulness of electron density data for explaining ionospheric dynamics at the polar latitudes.

The presented paper will address the following questions.

1. Do amplitude and phase scintillation indices show different variation patterns during the pre- and post-geomagnetic onset time over Antarctica?

2. If yes, then why? Can we find similar information from both amplitude and phase scintillation index time series during the geomagnetic storm.

3. What combination of IMF By and Bz generally trigger ionospheric irregularities pass deep inside the polar cap from the dayside cusp sector at the South Pole?

The next section of the paper will provide the detailed information about the event we chose and the type of the data set used to investigate it, for answering the questions raised above.

\section{Data and methodology}

In the presented paper, we are focusing on dayside ionosphere over the southern hemisphere. Fortunately, the GPS TEC receiver and the GPS scintillation receiver GSV4004b at South Pole scintillation receiver (location: $-89.99^{\circ}$ geographic latitude, $93.77^{\circ}$ geographic longitude) and McMurdo Station scintillation receiver (location: $-77.85^{\circ}$ geographic latitude, $166.66^{\circ}$ geographic longitude) covers most of the interesting dayside region. The GPS TEC and scintillation data are freely available at the Madrigal Database (http://madrigal.haystack.mit.edu/madrigal/). The TEC data is the vertical TEC (VTEC) defined in TEC using $\left(1 \mathrm{TECu}=10^{16}\right.$ electrons $\left./ \mathrm{m}^{2}\right)$. We have used raw GNSS data, which is in RINEX 3.01 format for GPS and GLONASS observations. This GNSS dataset is freely available at ftp://cddis.gsfc.nasa.gov/gnss/data/daily/. Many previous research studies have reported that the phase scintillation indices highly rely on the signal cutoff frequency. In general scintillation, receivers use Van Dierendonck et al. (1993) method for calculating the scintillation indices, where the detrending cutoff frequency is $0.1 \mathrm{~Hz}$ which is too low for the high latitudes. At the high latitudes ionospheric the Fresnel frequency sometimes exceeds from the cut-off frequency by an order of magnitude. If we choose the same cut-off frequency that we use for the low latitude this will artificially enhance the scintillation indices, and this enhancement is more visible in phase scintillation index due to phase fluctuation's direct dependence on the 
spectral index at the low temporal frequencies; than amplitude scintillation index (Forte and Radicella 2002). When the detrending cutoff frequency is $0.1 \mathrm{~Hz}$ this signal gets contaminated due to the refractive phase shits at the high latitudes and as a consequence, TEC gradients directly influence the phase scintillation index (Forte 2005; Forte and Radicella 2002; Béniguel et al. 2004; Beach 2006). Considering the problems related to the lower cutoff frequency of $0.1 \mathrm{~Hz}$, in the presented paper scintillation indices are calculated from the raw L1 signal carrier phase and intensity data. For detrending, the signal we have used $0.3 \mathrm{~Hz}$ cutoff frequency has been used. It is well known that the amplitude scintillation index as the ratio of the received signal power to the average signal power (Briggs and Parkin 1963), whereas the phase scintillation index is defined as the standard deviation of the detrended carrier phase (Fremouw et al. 1978). For minimizing the effect of multipath, we are using the data for elevation angle $>20^{\circ}$. Recent research studies presented in Priyadarshi et al. (2018a, 2018b) reveals the role of interplanetary magnetic field (IMF) components in controlling the drift of the plasma in the polar ionosphere during the disturbed earth directed solar events. We have presented IMF data together with the most of the observations presented in this paper. We also used high resolution (1-min) OMNI Solar wind magnetic field data at Earth's Bow Shock Nose (BSN), also 1-min provisional activity indices data available at OMNIWeb: High-Resolution OMNI (https://omniweb.gsfc.nasa.gov/form/omni_min.html). The high-resolution OMNI data used in the presented study combined 1-min averaged ACE, Wind, IMP 8 and Geotail magnetic field and plasma data shifted to a dynamic model bow shock nose location (7 minutes in our case). For targeting the dayside post magnetic noon sector of the precipitated particle at South Pole we have used The Defense Meteorological Satellite Program (DMSP) SSJ data which provides a complete energy spectrum of the low energy particles; Special Sensor Magnetometer (SSM) data, which provides information about the geomagnetic fluctuations associated with geophysical phenomena and Special Sensor Ion Electron Scintillation (SSIES) instrument observed data. SSIES instrument measures the ambient plasma by measuring (1) electron density and temperature; (2) ion density, temperature and drift velocity; and (3) scintillation at the DMSP orbital altitude (840 kilometers). The DMSP data is provided by NOAA at (http://www.ngdc.noaa.gov/stp/satellite/dmsp/). Antarctica also has a network of Super Dual Auroral Radar Network (SuperDARN) radars. This radar network currently has more than 30 low-power HF radars that target the ionosphere and they cover the land regions from the mid-latitude to the poles. These radars work in the frequency range of 8-20 MHz and they can target 16-24 beam directions. SuperDARN radars generally cover a region between $50^{\circ}$ to $80^{\circ}$ in steps of $3.3^{\circ}$ azimuth over a time period of 1-2 minute. The special resolution of the radar observation is about 45 kilometers. These observations are available at http://vt.superdarn.org/tiki-index. php. In the next section, we would present our observation using the instruments and data sources discussed above.

\section{Result and discussion}

A moderate geomagnetic storm occurred on 27 February 2014 and the storm associated shock arrived at Earth's magnetosphere at $\sim 17: 00$ UT (please see Fig. 1). It is well known that the storm-related shock arrival at the magnetosphere results in the enhancement in the solar dynamic pressure, prolonged southward IMF $\mathrm{Bz}$ and remarkable changes in the magnetospheric current system (Lugaz et al. 2015 and reference therein). Figure 1e shows at and after $\sim$ 17:00 UT Sym-H turns negative and achieves a value of around $-100 \mathrm{nT}$ at 21:30 UT. Figure $1 \mathrm{~d}$ shows the enhancement in the AE index $\sim 1000 \mathrm{nT}$ at 17:00 UT, this high-level AE index continued for few hours. Before 17:00 UT IMF Bz (in red; Fig. 1c) had a weak value, but just after the shock arrival IMF Bz started to fluctuate mostly southward and fluctuation in its amplitude was more than $10 \mathrm{nT}$. IMF By (in green) was negative between 17:00 to 18:30 UT; after 18:30 UT, IMF By turned positive until 22:00 UT, thereafter it turned negative. Bx had a very weak value until 17:00 UT, thereafter $\mathrm{Bx}$ was fluctuating between $+10 \mathrm{nT}$ to $0 \mathrm{nT}$. Figure 1a and Fig. $1 \mathrm{~b}$ show the amplitude and phase scintillation data scatter plot, which includes the data from the GPS GSV4004 South Pole scintillation receiver (location: $-89.99^{\circ}$ geographic latitude, $93.77^{\circ}$ geographic longitude) and McMurdo Station scintillation receiver (location: $-77.85^{\circ}$ geographic latitude, $166.66^{\circ}$ geographic longitude) observations. We have plotted both the amplitude and phase scintillation maps at a similar color scale varying between 0.05-0.2. Comparing Fig. 1a and Fig. 1b, it is very clear that just after the shock arrival time, enhancement in the phase scintillation index $(0.15-0.2)$ started to appear deep inside the polar cap region $-80-85^{\circ}$ MLAT ( 13:00-18:00 MLT). But, at this variation scale amplitude scintillation index do not show any significant changes, and it is hard to see any changes caused due to the geomagnetic storm. In conclusion, at the given variation scale (0.05-0.2 in our case) the phase scintillation index shows good coherence with the magnetospheric shock arrival effects. It is important to state here that this scale (0.05-0.2 in our case) is chosen so that we could see some storm time variations in the amplitude scintillation index in parallel to the phase scintillation index. The strongest phase scintillation during the geomagnetic storm time occurs in the vicinity of the high plasma convection region of the polar ionosphere, at the extended tongue of ionization and at the dense polar cap 
Fig. 127 February, 2014 Ionospheric scintillation, IMF, and provisional indices data (a) phase scintillation index; (b) amplitude scintillation index; (c) IMF Bx (in blue), $\mathrm{By}$ (in green), $\mathrm{Bz}$ (in red); (d) $\mathrm{AE}$ (in red), $\mathrm{AU}$ (in green), $\mathrm{AL}$ (in blue); and (e) Sym-H/Dst in nT
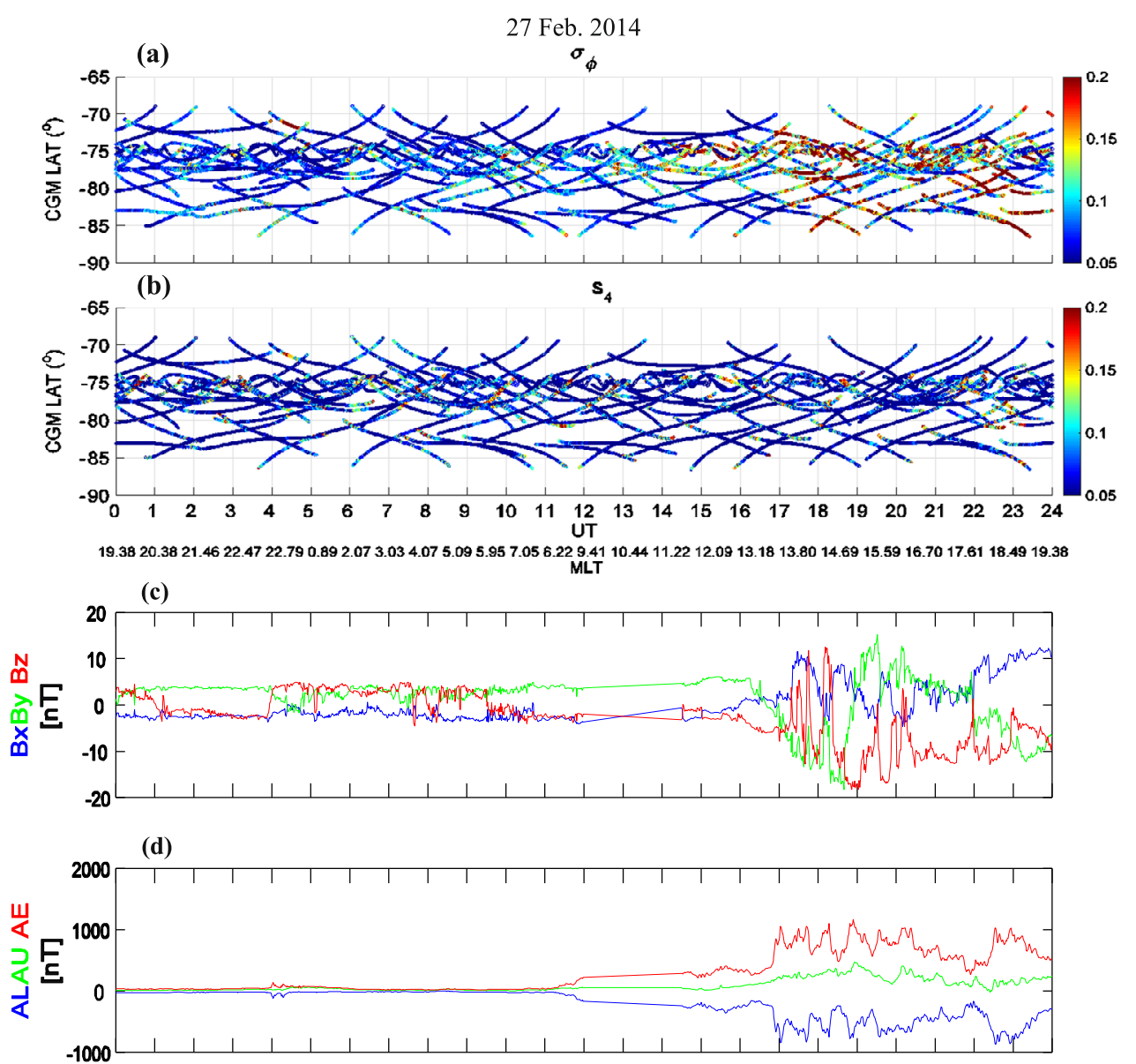

(e)

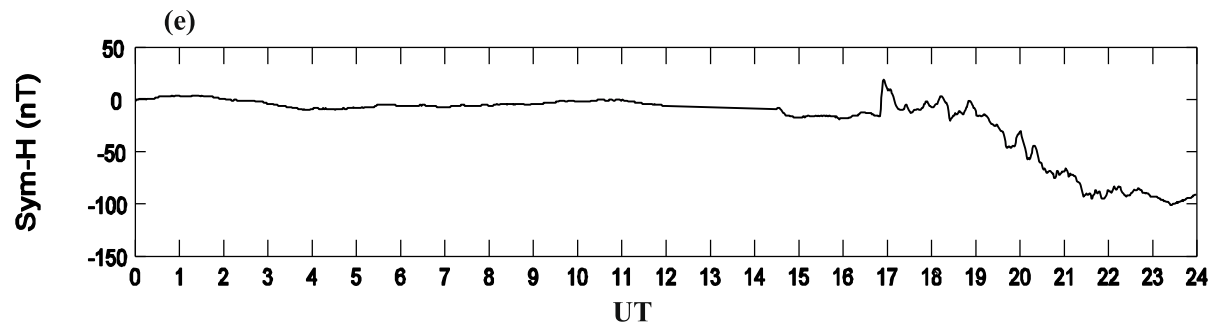

patches (Prikryl et al. 2013). Such enhanced phase scintillation may be associated with the patches, which are the large-scale region from 100-1000 kilometers of enhanced electron density. At the edges of these patches generally, the electron density fluctuations are very high, as the boundaries of the patches are surrounded by low electron density region (Burston et al. 2009; Kivanç and Heelis 1997). Scintillation can be observed on any part of the patch but, mostly strong scintillations are observed on the trailing edge of the patches (Kivanç and Heelis 1997). Whereas, amplitude scintillation index appears neutral at the similar variation scale of the $\sigma_{\varphi}$ and doesn't seem influenced as the storm-related shock arrives at the dayside cusp region. Generally, amplitude fading of GNSS signals appears low during such storm events and $50 \mathrm{~Hz}$ signals need analysis only for studying short time signal fading at the polar ionosphere (Smith et al. 2008; Kin- rade et al. 2013). For knowing the irregularity structure, it would be good to check the GPS derived total electron content and DMSP SSJ and SSES sensor data during the storm shock arrival time.

Figure $2 \mathrm{a}$ and Fig. $2 \mathrm{~b}$ show the GPS TEC over Antarctica at 18:45 UT and 19:20 UT. This is the time at which we have observed strong scintillation deep inside the polar cap. Both figures show clearly the SED between $-60-80^{\circ}$ at $\sim 12-$ 15 MLT. In Fig. 2b, SED noticeably entering at the South Pole at $\sim 14-15$ MLT. If we see the DMSP F17 (Fig. 2c) and F16 (Fig. 2d) passes over the post-noon sector of South Pole, it shows energetic particle precipitation $10-10^{4} \mathrm{eV}$ between $\sim-60-85^{\circ}$ MLAT at $\sim 16-17$ MLT (Fig. 2c) and between $\sim-60-85^{\circ}$ MLAT at $\sim 17-18$ MLT. The horizontal and vertical velocity of the particles was considerably high in this sector, which indicates high energetic particle precip- 
TOTAL ELECTRON CONTENT 27/Feb/2014 18:40:00.0 Median Filtered, Threshold $=0.10 \quad 27 / \mathrm{Feb} / 2014$ 18:45:00.0

(a)

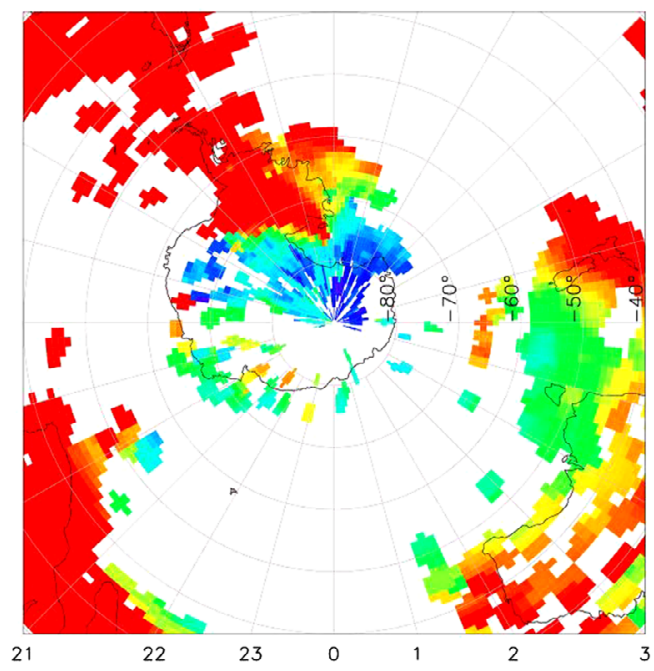

TOTAL ELECTRON CONTENT 27/Feb/2014 19:15:00.0 Median Filtered, Threshold $=0.10$ 27/Feb/2014 19:20:00.0

(b)

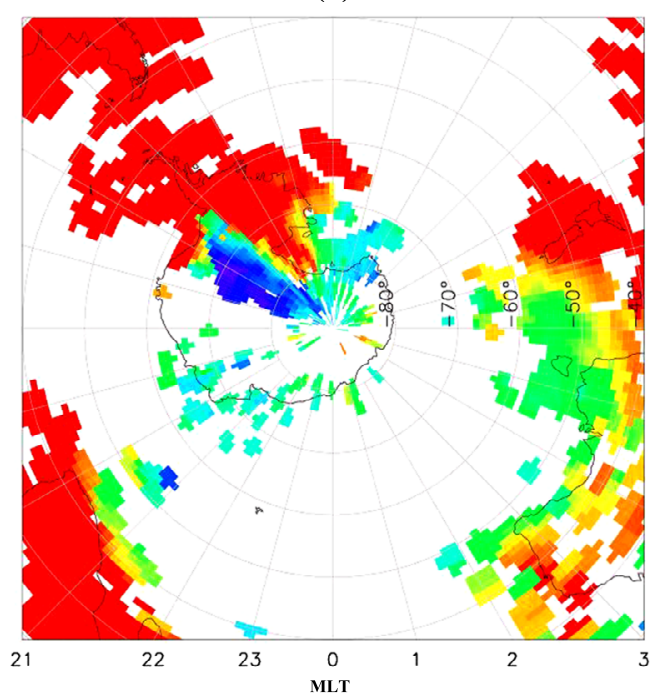

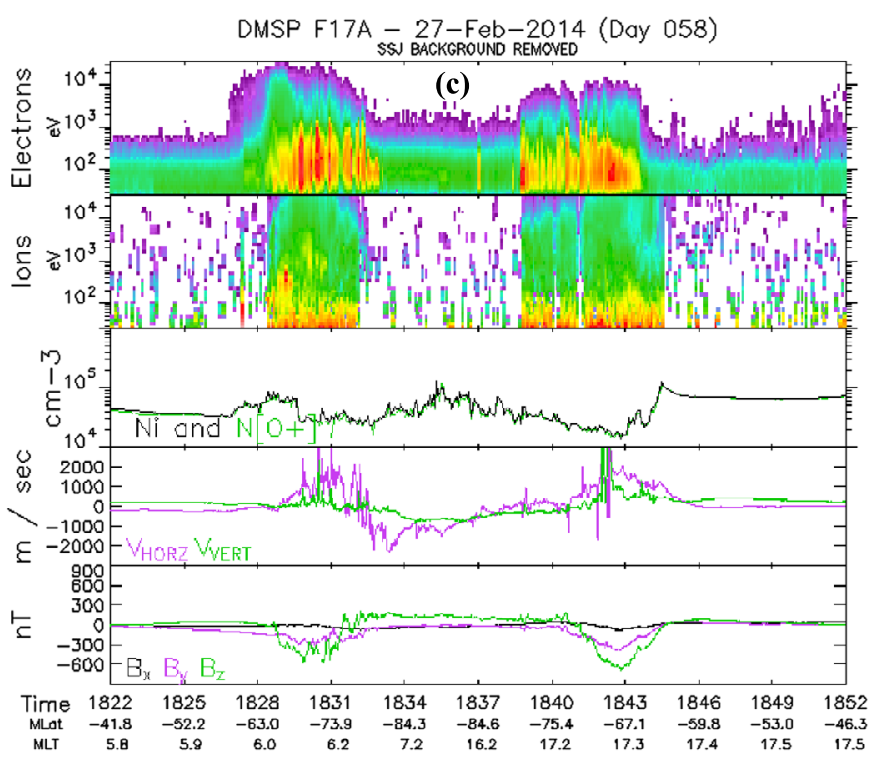

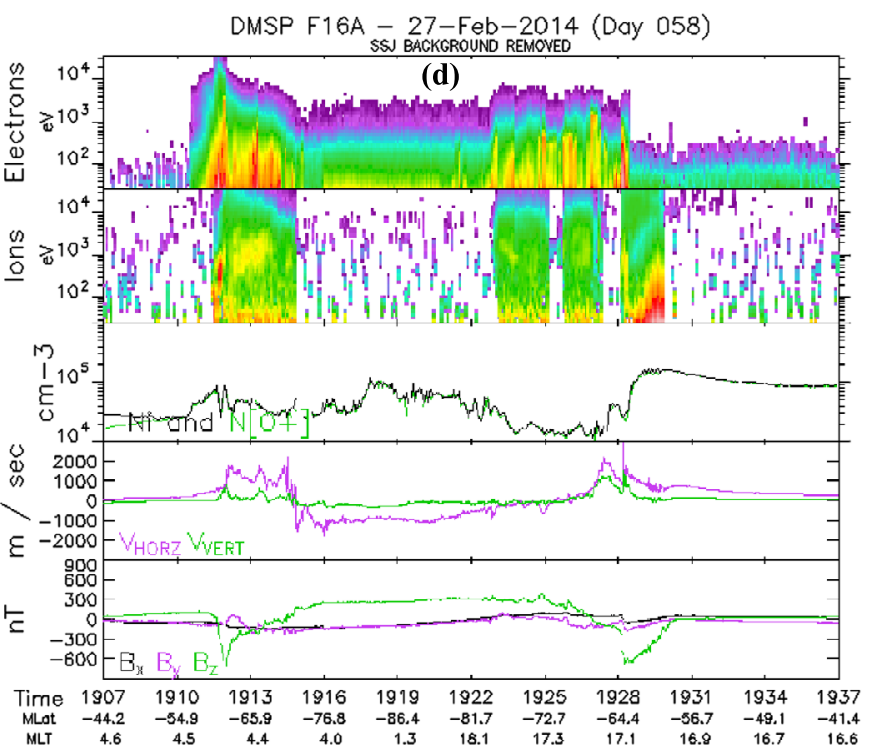

Fig. 2 TEC (a) at 18:45 UT; (b) at 19:20 UT; and DMSP SSIES, SSJ Experiment data (c) F17; (d) F16, on 27 February, 2014

itation as well as enhanced irregularity convection velocity. The particle density was constant in this region and the local magnetic field components measured by the DMSP onboard magnetometer By and Bz both were negative in these sectors. Generally, we see the ionospheric irregularities near the magnetic noon and post magnetic noon sectors of Antarctica. It would be interesting to see the ionospheric amplitude and phase scintillation variation in those regions. High latitude scintillation is mostly due to the magnetospheric processes and the scintillations are most severe during the geomagnetic storm events (Basu et al. 2002). Mitchell et al. (2005) studied the severe ionospheric storm time scintilla- tion of 30 October 2003 and found that a narrow stream of enhanced electron density plasma has crossed the polar cap in anti-sunward direction. These enhanced electron density plasma stream anti-sunward and across the polar cap are consistent with the southward Bz (Mitchell et al. 2005). Amplitude and phase scintillation on the several GPS satellites have been observed at the edges of the enhanced electron density narrow stream and gradient drift instability was proposed as a most suitable mechanism for this scintillation event (Mitchell et al. 2005).

Figures $3 \mathrm{a}$ and $3 \mathrm{~b}$ show the amplitude and phase scintillation index over the South Pole between 15:00 UT to 
Fig. 3 15:00 UT to 21:00 UT,

(a) phase scintillation over

South Pole $-70-80^{\circ}$ MLAT,

(b) amplitude scintillation over South Pole $-70-80^{\circ}$ MLAT;

(c) amplitude and phase

scintillation along $90-100^{\circ} \mathrm{E}$ at

MLT 12:00; (d) amplitude and

phase scintillation along

$170-180^{\circ} \mathrm{E}$ at MLT 15:00, over

South Pole $-70-80^{\circ}$ MLAT (a) $\sigma_{\phi} 27 / 02 / 2014$

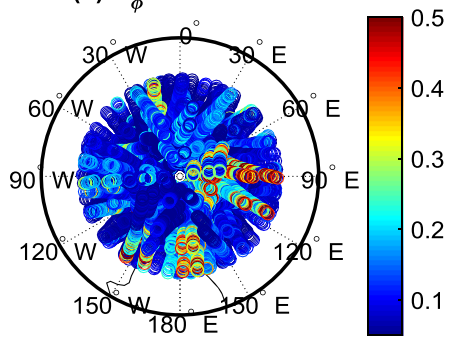

(b) $\mathrm{S}_{4} 27 / 02 / 2014$

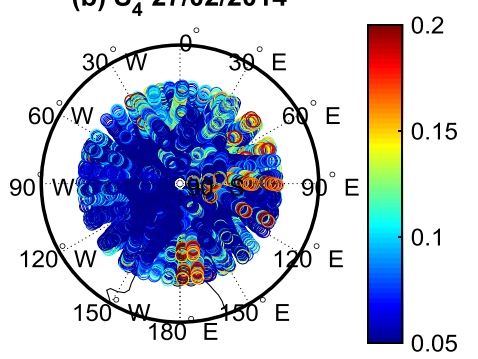

(c)

27 February 2014; 12:00 MLT

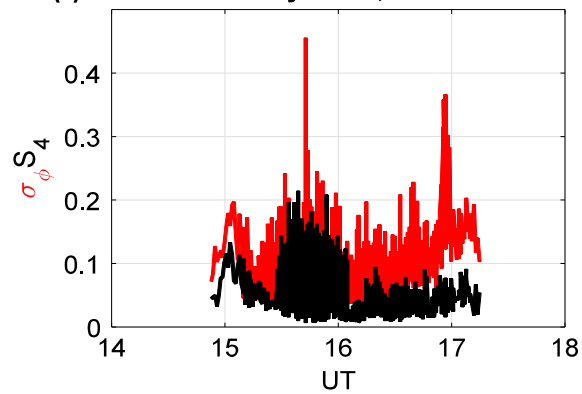

(d)

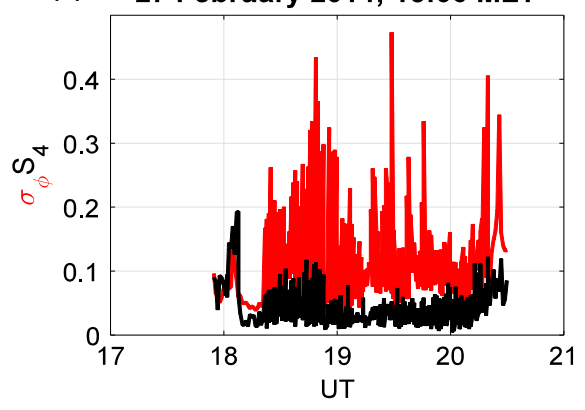

21:00 UT at $\sim-70-80^{\circ}$ MLAT, respectively. Figure $3 \mathrm{a}$ and Fig. $3 \mathrm{~b}$ are the polar scatter plots, where the geographic longitude is varying along the rim of the map whereas, the geographic latitude is varying along the radii of the polar scintillation map. We have optimized the amplitude and phase scintillation index variation scale, where the phase scintillation (Fig. 3a) is varying between $0.05-0.5$, whereas, amplitude scintillation (Fig. 3b) is varying between 0.05-0.2. This optimization is just to demonstrate that the amplitude and phase scintillation in the polar region vary in the same way but, at the different range of the numerical scales. If we compare Fig. 3a and Fig. 3b we see that they show the similar enhancement in the amplitude and phase scintillation indices between $90-100^{\circ} \mathrm{E}, 110-120^{\circ} \mathrm{E}$ and $170-180^{\circ}$ E. Figure $3 \mathrm{c}$ shows the simultaneous variation of amplitude as well as phase scintillation along $90-100^{\circ} \mathrm{E}$ at MLT 12:00 over the South Pole between $-70-80^{\circ}$ MLAT. This map covers the scintillation data before and after the geomagnetic storm associated shock arrival. Between 15:0016:45 UT, the amplitude and phase scintillation variation are mostly alike but the numerical value of the phase scintillation index is higher throughout this duration. Just near the 17:00 UT, $\sigma_{\varphi}$ enhanced at once, but, we don't see a conjugate peak in the $\mathrm{S}_{4}$ (see Fig. 3c). This peak indicates the geomagnetic storm associated shock onset at the magnetic noon cusp sector. Figure $4 \mathrm{~d}$ shows the variation of the $\mathrm{S}_{4}$ and $\sigma_{\varphi}$ along $170-180^{\circ}$ E at MLT 15:00, over the South Pole between $-70-80^{\circ}$ MLAT. This variation is completely under the influence of the geomagnetic storm associated effects. Phase scintillation, without significant amplitude scintillation on the GPS L-band signal, is mostly due to the high- velocity large-scale structures, spreading between $\mathrm{E}$ and $\mathrm{F}$ ionospheric layers (Forte et al. 2017). As we can see in Fig. 4 that the $\sigma_{\varphi}$ is much larger than the $\mathrm{S}_{4}$, if we compare it with Fig. 3c, which indicate the irregularities generating the scintillation have very high speed and they are mostly large-scale structures. Both the Fig. 3c and Fig. 3d indicates similar variations and their enhanced peaks are coherent to each other. The only difference is in the variation scales of $\mathrm{S}_{4} / \sigma_{\varphi}$. It is evident that under the influence of geomagnetic storm the difference in the variation scale of $\sigma_{\varphi}$ and $\mathrm{S}_{4}$ at the dayside cusp sector enhances but, still both the scintillation indices follow the same time series variation trend. At the same numerical scale phase scintillation occurs without any significant enhancement in the amplitude scintillation is because of the irregularity generation mechanism that injects free energy into the system of the order of kilometers scale and even larger scales, but, this ionospheric irregularity generation mechanism does not allow free energy injection in the system of the scale lower than the Fresnel scale (Forte and Radicella 2002).

Figure 4 compares Halley beam 10 observations with the GPS scintillation receiver data. The radar beam is targeting between $170-180^{\circ}$ E geographic longitude (Fig. 4a). Figure $4 \mathrm{~b}$ shows a thick radar power scatter band (in the black color dotted rectangle) at $\sim 18: 45$ UT spreading between $-68^{\circ}$ to $-76^{\circ}$ MLAT. Radar velocity observation shows in Fig. 4c confirms this irregularity band is mainly due to a high-speed irregularity structure, which is moving away from the radar's beam by a speed of $\sim 400$ meters/second. There are also a few low-speed positive velocity components present in this irregularity band. The spe- 
Fig. 427 February 2014, (a) Halley radar beam 10 direction (b) radar power scatter, (c) velocity, (d) specific width of the spectrum between, (e) GPS TEC in the Halley radar beam 10 direction, during 17:00-24:00 UT; (f) phase scintillation, (g) amplitude scintillation at $170-180^{\circ} \mathrm{E}$ during 18:40-18:50 UT observed by South Pole scintillation receiver in the direction of the Halley radar beam 10 on 27 February 2014

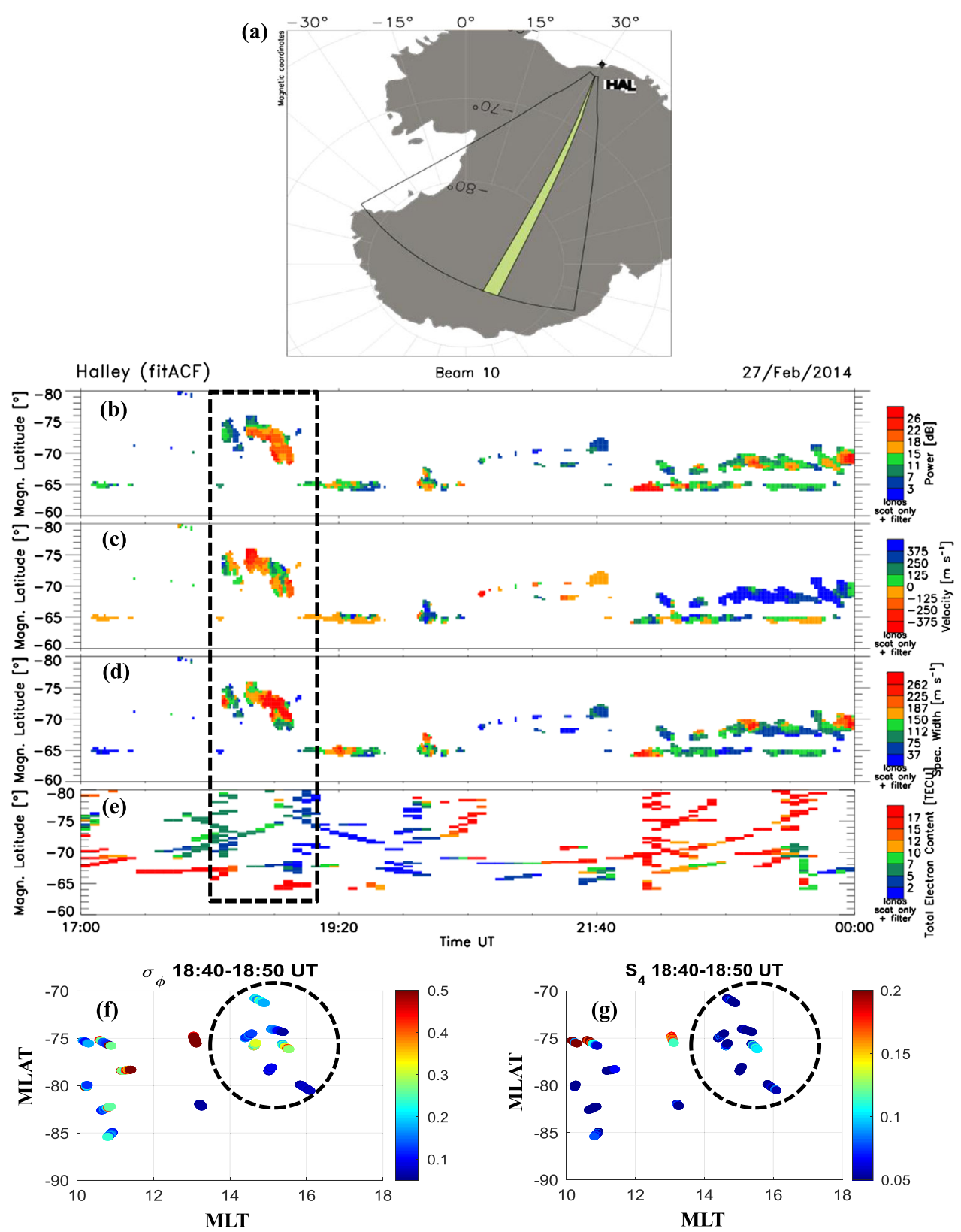

cific width of the moving away band is $>260$ meters/second (Fig. 4d). We do not have enough GPS TEC observation collocated with this irregularity band except a thin low TEC line of $\sim 7 \mathrm{TECu}$. This radar irregularity structure was in the post magnetic noon sector of South Pole. We have plotted 10-minute amplitude and phase scintillation data and it shows that the scintillation observations fall between 1416 MLT (shows inside the black color dotted circle). We have set the numerical scale for phase scintillation from 0.05 to 0.5 (Fig. 4f) and for the amplitude scintillation (Fig. 4g) from 0.05 to 0.2 . Figure $4 \mathrm{f}$ and Fig. $4 \mathrm{~g}$ demonstrate the high-velocity ionospheric irregularity structures give rise to strong phase, but, moderate to weak amplitude scintillation. After 18:50 UT, Halley beam 10 radar scatters shrinks be- tween -60 to $-70^{\circ}$ MLAT. In these lower MLAT regions, we have poor availability of the scintillation data. But, this figure served its purpose comparing the storm time highvelocity ionospheric irregularity and their associated ionospheric amplitude/phase scintillation index in the post magnetic noon sector. The irregularity structure is shown in the black dotted rectangle in Figs. 4b, 4c and 4d, seems quite similar to the TOI, as it looks locally structured and its scale size is a few tens of kilometers scale (van der Meeren et al. 2014). The enhancement in the amplitude and phase scintillation associated with this TOI like irregularity structure indicates that this ionospheric irregularity structure is highly structured (van der Meeren et al. 2014). But, still, amplitude scintillation index is providing the identical enhance- 
Fig. 527 February 2014, South Pole (a) Dome $\mathrm{C}$ beam 0 radar direction, (b) radar power scatter, (c) radar velocity, (d) specific width, (e) GPS TEC between $0-24$ UT in the direction $170-180^{\circ} \mathrm{E}$; time series of (f) phase scintillation and (g) amplitude scintillation at $170-180^{\circ}$ during $0-24$ UT

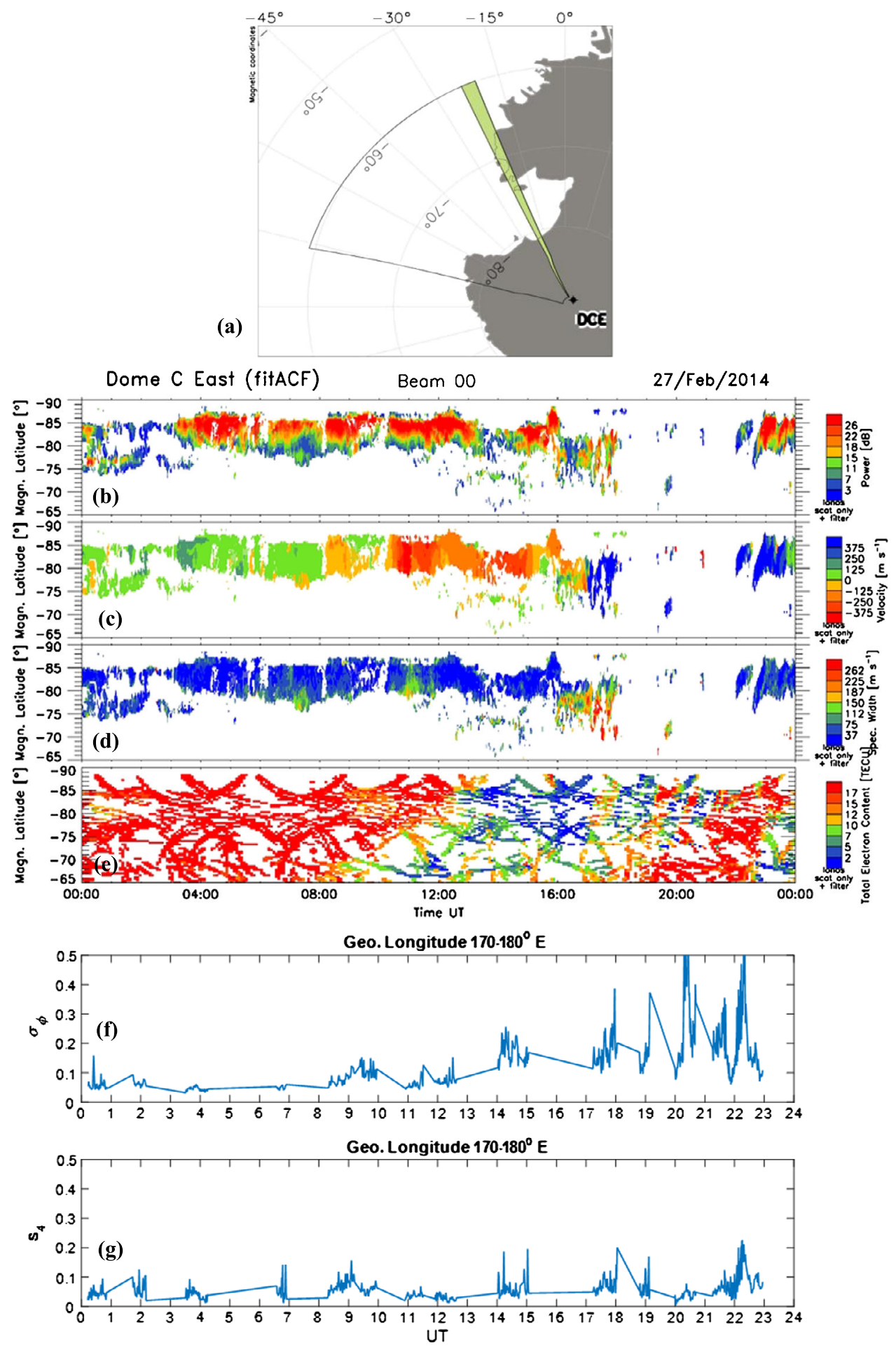

ment trend as the phase scintillation index associated with this structured large-scale irregularity structure at comparatively lower variation scale.

Figure 5a shows the Dome $\mathrm{C}$ radar beam 00 ray paths. This radar spots between $170-180^{\circ}$ E geographic longitude and we are showing here a time series from 0:00 to 24:00 UT. Figures 5b, 5c, 5d, and 5e show a thin iono- spheric irregularity band present between $-70^{\circ}$ to $-85^{\circ}$ MLAT during 0:00-16:00 UT. After 16:00 UT the radar backscatter structure shrinks between $-70^{\circ}$ to $-80^{\circ}$ MLAT. Radar velocity measurements are shown in the Fig. 5c, manifest that before 16:00 UT ionospheric irregularity structures were mostly unidirectional at a time duration, either coming towards radar beam or moving away. But, just after 
16:00 UT, and between 16:00-18:00 UT, we see not only shrinks in the ionospheric irregularity band, but, also the existence of two opposite high-velocity components, and their velocity is around \pm 400 meters/second. This is clearly a dayside geomagnetic storm onset polar ionospheric feature. The GPS TEC data between $-70^{\circ}$ to $-85^{\circ}$ MLAT (Fig. 5e) was high during 0:00-12:00 UT and thereafter, it has a low value from 12:00-16:00 UT. During 17:00-18:00 UT GPS TEC data also shows sudden strong enhancement in the TEC from $-70^{\circ}$ to $-90^{\circ}$ MLAT, which clearly shows that the high-density plasma is coming into the South Pole from the dayside sub-auroral latitudes. Figure $4 \mathrm{f}$ and Fig. $4 \mathrm{~g}$ show the time series of the phase and amplitude scintillation in the geographic longitude direction from $170-180^{\circ} \mathrm{E}$ at $-70^{\circ}$ to $-80^{\circ}$ MLAT, respectively. We observe a good parity in the amplitude and phase scintillation indices between 0:00 UT to 16:00 UT. After 17:00 UT the $\sigma_{\varphi}$ enhancements appear a little more than the $\mathrm{S}_{4}$, but, still, both have quite a good resemblance until 19:00 UT. During 20:00 to 23:00 UT $\sigma_{\varphi}$ peaks are much larger than the $\mathrm{S}_{4}$. Figure 5 confirms that during the geomagnetic storm influence, the dayside ionospheric irregularity convection speed is much larger than during the quiet period. Ionospheric phase scintillation is very much vulnerable to the high-speed irregularity structure because such high-speed large-scale structures very easily change the phase of the GPS signal as compared to the amplitude. Therefore, during such a disturbed period different numerical scale should be used for the amplitude and phase scintillation studies (van der Meeren et al. 2014 and references therein). Our all the results show if the proper variation scale is chosen amplitude scintillation index may also appear a useful ionospheric scintillation index for the high latitude. It is well understood that during the initial phase of the geomagnetic storm number of the ground scatter signal increases but, during the intense phase of the geomagnetic storm, the ground backscatter decreases or may completely disappear (Zolotukhina et al. 2016). These changes in the ground backscatter depends on many factors such as compression of the magnetosphere, expansion of the convection cell and changes in the atmospheric composition during the initial and main phase of the geomagnetic storm (Zolotukhina et al. 2016). The decrease in the Dome C East radar backscatter between 18:00-22:00 UT is certainly caused due to all of the reasons mentioned above.

\section{Summary and conclusion}

The research work presented dayside cusp and post magnetic noon region geomagnetic storm-time ionospheric response on 27 February 2014 over Antarctica. We have also studied ionospheric amplitude and phase scintillation associated with the SED and TOI structures. However, at the given variation scale (0.05-0.2 in our case) the phase scintillation index showed a good coherence with the aftershock arrival effects. Whereas, amplitude scintillation index appears neutral and doesn't get influenced after shock arrival the dayside cusp region. The GPS TEC data shows the SED over the dayside post noon cusp region and some high density fragmented TOI entering into the polar region from the post noon dayside cusp region. IMF $\mathrm{Bz}$ is responsible for the dayside reconnection and at the same time when IMF By is negative it makes the duskside cell more active and cusp is shifted towards post noon region. This allows insertion of the high-density plasma deep in the polar cap. The DMSP F16 and F17 pass over the post magnetic noon sector of South Pole indicate the energetic particle precipitation energy ranging for $10-10^{4} \mathrm{keV}$. The onboard magnetometer data shows both the By and Bz components of the local magnetic fields very negative. DMSP data shows that the geomagnetic storm-time ionospheric irregularities have relatively high horizontal velocity component in the post noon sector of South Pole. In the presented study for the first time, it is demonstrated that amplitude and phase scintillation data during the storm time show similar variation trends and the possible reasons of difference in their numerical scales are also discussed. During the storm time, at the same numerical scale phase scintillation occurs without any significant enhancement in the amplitude scintillation near the polar regions appears because of the irregularity generation mechanism that injects free energy into the system of the order of kilometers scale and even larger scales, but, this ionospheric irregularity generation mechanism does not allow free energy injection in the system of the scale lower than the Fresnel scale. In order to check the parity in the amplitude and the phase scintillation indices at the South Pole, we have optimized the numerical variation scale of the amplitude scintillation to $0.05-0.2$ and the phase scintillation to $0.05-0.5$. At this scale their variation is alike. At the optimized variation scale, scintillation indices have shown the pre- as well as post-geomagnetic storm time enhancement between $90-120^{\circ} \mathrm{E}$ and $170-180^{\circ} \mathrm{E}$ geographic longitudinal direction. We found that during the pre-storm onset period the difference in variation scale of the amplitude and phase scintillation was very low as compared to their relative variation after the onset of the geomagnetic storm. We have checked the 24-hour radar observation along with the amplitude and phase scintillation time series. We also observed the high ionospheric irregularity convection speed during the geomagnetic storm time enhances the peaks of the phase scintillation index to a relatively higher level as compared to the amplitude scintillation. But, amplitude scintillation shows the storm associated enhancement in its time series at the South Pole. Radar and GPS scintillation receiver data confirm that before the onset of the geomagnetic storm, amplitude and phase scintillation variations have great parity. Therefore, if the proper amplitude scintillation variation 
scale is chosen and both the amplitude and phase scintillation indices are optimized at a different numerical scale, we can get very similar information from both the indices in the polar region as well. There is no doubt that the amplitude scintillation index is more stable and reliable scintillation index than the phase scintillation index for the polar and high latitude ionosphere if we optimize its numerical variation scale properly.

Acknowledgements This work was supported by "China Postdoctoral International Exchange Program" Grant from the Institute of Space Sciences Shandong University, China; the National Natural Science Foundation (grants 41574138, 41274149, and 41274148); the Shandong Provincial Natural Science Foundation (grant JQ201412); and the International Collaboration Supporting Project, Chinese Arctic and Antarctic Administration (IC201511). We gratefully acknowledge support from the USA, National Science Foundation grants PLR1248062, PLR -1247975, and PLR-1248087. Data used in the present paper have been downloaded from Madrigal database [http://madrigal. iggcas.ac.cn/madrigal/], NASAOMINIWEB server [http://omniweb. gsfc.nasa.gov/] and NOAA [http://www.ngdc.noaa.gov/stp/satellite/ $\mathrm{dmsp} /$ ]. We also acknowledge the use of SuperDARN data [http://vt. superdarn.org/tiki-index.php]. SuperDARN is a collection of radars funded by national scientific funding agencies of Australia, Canada, China, France, Japan, South Africa, United Kingdom and the United States of America. We would also like to thank Dr. Patricia Doherty, Institute for Scientific Research for the data, from the CEDAR Madrigal database, which is available at https://w3id.org/cedar?experiment_list $=$ experiments $3 / 2018 / \mathrm{dms} / 02 \mathrm{jan} 18 \&$ file_list $=\mathrm{dms} \_20180102 \_15 \mathrm{~s} 1$. 001.hdf5. This research work is partially supported by International Space Science Institute-Beijing China (ISS-BJ).

Open Access This article is distributed under the terms of the Creative Commons Attribution 4.0 International License (http:// creativecommons.org/licenses/by/4.0/), which permits unrestricted use, distribution, and reproduction in any medium, provided you give appropriate credit to the original author(s) and the source, provide a link to the Creative Commons license, and indicate if changes were made.

\section{References}

Basu, S., Groves, K.M., Basu, Su., Sultan, P.J.: Specification and forecasting of scintillations in communication/navigation links: current status and future plans. J. Atmos. Sol.-Terr. Phys. 64, 17451754 (2002). https://doi.org/10.1016/S1364-6826(02)00124-4

Beach, T.L.: Perils of the GPS phase scintillation index $\left(\sigma_{\varphi}\right)$. Radio Sci. 41, RS5S31 (2006). https://doi.org/10.1029/2005RS003356

Béniguel, Y., Forte, B., Radicella, S.M., Strangeways, H.J., Gherm, V.E., Zernov, N.N.: Scintillations effects on satellite to Earth links for telecommunication and navigation purposes. Ann. Geophys. 47(2-3), 1179-1199 (2004). https://doi.org/10.4401/ag-3293

Briggs, B., Parkin, I.: On the variation of radio star and satellite scintillations with zenith angle. J. Atmos. Terr. Phys. 25(6), 339-366 (1963). https://doi.org/10.1016/0021-9169(63)90150-8

Burston, R., Astin, I., Mitchell, C., Alfonsi, L., Pedersen, T., Skone, S.: Correlation between scintillation indices and gradient drift wave amplitudes in the northern polar ionosphere. J. Geophys. Res. 114, A07309 (2009). https://doi.org/10.1029/2009JA014151

D’Angelo, G., Piersanti, M., Alfonsi, L., Spogli, L., Clausen, L., Boy, N., Coco, I., Li, G., Baiqi, N.: The response of high latitude ionosphere to the 2015 St. Patrick's day storm from in situ and ground based observations. Adv. Space Res. 62(3), 638-650 (2018). https://doi.org/10.1016/j.asr.2018.05.005

Forte, B.: Optimum detrending of raw GPS data for scintillation measurements at auroral latitudes. J. Atmos. Sol.-Terr. Phys. 67(12), 1100-1109 (2005). https://doi.org/10.1016/j.jastp.2005.01.011

Forte, B., Radicella, S.M.: Problems in data treatment for ionospheric scintillation measurements. Radio Sci. 37(6), 1096 (2002). https:// doi.org/10.1029/2001RS002508

Forte, B., Coleman, C., Skone, S., Häggström, I., Mitchell, C., Da Dalt, F., Panicciari, T., Kinrade, J., Bust, G.: Identification of scintillation signatures on GPS signals originating from plasma structures detected with EISCAT incoherent scatter radar along the same line of sight. J. Geophys. Res. Space Phys. 122, 916-931 (2017). https://doi.org/10.1002/2016JA023271

Fremouw, E.J., Leadabrand, R.L., Livingston, R.C., Cousins, M.D., Rino, C.L., Fair, B.C., Long, R.A.: Early results from the DNA wideband satellite experiment-complex-signal scintillation. Radio Sci. 13(1), 167-187 (1978). https://doi.org/10.1029/ RS013i001p00167

Jin, Y., Moen, J.I., Oksavikand, K., Spicher, A., Clausen, L.B.N., Miloch, W.J.: GPS scintillations associated with cusp dynamics and polar cap patches. J. Space Weather Space Clim. 7, A23 (2017). https://doi.org/10.1051/swsc/2017022

Kinrade, J., Mitchell, C.N., Yin, P., Smith, N., Jarvis, M.J., Maxfield, D.J., Rose, M.C., Bust, G.S., Weatherwax, A.T.: Ionospheric scintillation over Antarctica during the storm of 5-6 April 2010. J. Geophys. Res. 117, A05304 (2012). https://doi.org/10.1029/ 2011JA017073

Kinrade, J., Mitchell, C.N., Smith, N.D., Ebihara, Y., Weatherwax, A.T., Bust, G.S.: GPS phase scintillation associated with optical auroral emissions: first statistical results from the geographic South Pole. J. Geophys. Res. Space Phys. 118, 2490-2502 (2013). https://doi.org/10.1002/jgra.50214

Kivanç, Ö, Heelis, R.A.: Structures in ionospheric number density and velocity associated with polar cap ionization patches. J. Geophys. Res. 102(A1), 307-318 (1997). https://doi.org/10.1029/ 96JA03141

Li, G.Z., Ning, B.Q., Ren, Z.P., Hu, L.H.: Statistics of GPS ionospheric scintillation and irregularities over polar regions at solar minimum GPS. Solutions 14(4), 331-341 (2010)

Lugaz, N., Farrugia, C.J., Huang, C.-L., Spence, H.E.: Extreme geomagnetic disturbances due to shocks within CMEs. Geophys. Res. Lett. 42, 4694-4701 (2015). https://doi.org/10.1002/ 2015GL064530

Mitchell, C.N., Alfonsi, L., De Franceschi, G., Lester, M., Romano, V., Wernik, A.W.: GPS TEC and scintillation measurements from the polar ionosphere during the October 2003 storm. Geophys. Res. Lett. 32, L12S03 (2005). https://doi.org/10.1029/2004GL021644

Moen, J., Oksavik, K., Alfonsi, L., Daabakk, Y., Romano, V., Spogli, L.: Space weather challenges of the polar cap ionosphere. J. Space Weather Space Clim. 3, A02 (2013). https://doi.org/10.1051/ swsc/2013025

Prikryl, P., Jayachandran, P.T., Mushini, S.C., Pokhotelov, D., MacDougall, J.W., Donovan, E., Spanswick, E., Maurice, J.P.S.: GPS TEC, scintillation and cycle slips observed at high latitudes during solar minimum. Ann. Geophys. 28(6), 1307-1316 (2010)

Prikryl, P., Ghoddousi-Fard, R., Kunduri, B.S.R., Thomas, E.G., Coster, A.J., Jayachandran, P.T., Spanswick, E., Danskin, D.W.: GPS phase scintillation and proxy index at high latitudes during a moderate geomagnetic storm. Ann. Geophys. 31(5), 805-816 (2013). https://doi.org/10.5194/angeo-31-805-2013

Prikryl, P., Jayachandran, P.T., Chadwick, R., Kelly, T.D.: Climatology of GPS phase scintillation at northern high latitudes for the period from 2008 to 2013. Ann. Geophys. 33, 531-545 (2015a). https:// doi.org/10.5194/angeo-33-531-2015 
Prikryl, P., Jayachandran, P.T., Chadwick, R., Kelly, T.D.: Climatology of GPS phase scintillation at northern high latitudes for the period from 2008 to 2013. Ann. Geophys. 33, 531-545 (2015b). https://doi.org/10.5194/angeo-33-531-2015

Prikryl, P., et al.: GPS phase scintillation at high latitudes during the geomagnetic storm of 17-18 March 2015. J. Geophys. Res. Space Phys. 121, 10,448-10,465 (2016). https://doi.org/10.1002/ 2016JA023171

Priyadarshi, S., Zhang, Q.-H., Thomas, E., Spogly, L., Claudio, C.: Polar traveling ionospheric disturbances inferred with the B-spline method and associated scintillations in the southern hemisphere. Adv. Space Res. (2018a). https://doi.org/10.1016/j.asr.2018. 08.015

Priyadarshi, S., Zhang, Q.-H., Ma, Y.-Z., Xing, Z.-Y., Hu, Z.J., Li, G.Z.: Ionospheric scintillation study during the selected aurora observed at the Chinese Yellow River Station $\mathrm{Ny}^{\circ}$ Alesund in the Arctic. Front. Astron. Space Sci. (2018b). https://doi.org/10.3389/ fspas. 2018.00026

Smith, A.M., Mitchell, C.N., Watson, R.J., Meggs, R.W., Kintner, P.M., Kauristie, K., Honary, F.: GPS scintillation in the high Arctic associated with an auroral arc. Space Weather 6, S03D01 (2008). ISSN:1542-7390

Spogli, L., Alfonsi, L., De Franceschi, G., Romano, V., Aquino, M.H.O., Dodson, A.: Climatology of GPS ionospheric scintilla- tions over high and mid latitude European regions. Ann. Geophys. 27(9), 3429-3437 (2009)

van der Meeren, C., Oksavik, K., Lorentzen, D., Moen, J.I., Romano, V.: GPS scintillation and irregularities at the front of an ionization tongue in the nightside polar ionosphere. J. Geophys. Res. Space Phys. 119, 8624-8636 (2014). https://doi.org/10.1002/ 2014JA020114

Van Dierendonck, A.J., Klobuchar, J., Hua, Q.: Ionospheric scintillation monitoring using commercial single frequency C/A code receivers. In: Proc. ION GPS-93, pp. 1333-1342. The Institute of Navigation, Arlington (1993)

Wang, Y., Zhang, Q.-H., Jayachandran, P.T., Lockwood, M., Zhang, S.-R., Moen, J., Xing, Z.-Y., Ma, Y.-Z., Lester, M.: A comparison between large-scale irregularities and scintillations in the polar ionosphere. Geophys. Res. Lett. 43, 4790-4798 (2016). https:// doi.org/10.1002/2016GL069230

Wernik, A.W., Alfonsi, L., Materassi, M.: Ionospheric irregularities, scintillation and its effect on systems. Acta Geophys. Pol. 52(2), 237-249 (2004)

Zolotukhina, N.A., Kurkin, V.I., Polekh, N.M., Romanova, E.B.: Backscattering dynamics during intense geomagnetic storm as deduced from Yekaterinburg radar data March 17-22, 2015. J. Sol.Terr. Phys. 2(4), 31-54 (2016). https://doi.org/10.12737/24272 